\title{
A Review of Safety Issues among Small Grade Contractors in Construction Industry
}

\author{
Noorhayatie Yusof ${ }^{1}$, and Mohd Saidin Misnan ${ }^{1 *}$ \\ ${ }^{1}$ Department of Quantity Surveying, Faculty of Built Environment \& Surveying, Universiti Teknologi Malaysia, \\ 81310 Johor Bahru, Johor, Malaysia
}

\begin{abstract}
The construction industry is one of the largest industries in Malaysia. There were too many factors that contribute to construction project success. Construction industry comprises different participants including clients, consultants, and contractors (as construction business) that perform different roles from conception in order to complete the project. The contractors in Malaysia were categorized into seven Grades of contractors starting from contractor G1 to G7. These categories were graded based on a number of employees and the value of the project. In Malaysia, G1 to G4 contractors (small grade contractors) are the highest company were registered with the Construction Industry Development Board (CIDB). Unfortunately, small grade contractors are widely exposed to the highest rate of accidents or risky compared to medium and large grade contractors (G5-G7) in this industry. In order to adequately clarify the issues on this safety matter, this paper has discussed the problems faced by small grade contractors that influence the implementation of safety practice in a construction site. The objective of study is to identify the problems in small grade contractors in order to implement safety practice on site. This study was focused on small grade contractor in Malaysia. The data for this study were supported by previous studies are reported in the journal; statistic of accidents in the construction industry by Department of Occupational Safety and Health (DOSH); contractor information; statistic of contractors are registered under CIDB; safety book; and internet sources. This study had found that the small grade contractors have some issues related to safety practice whereas they did not have proper standard of safety (general safety act and regulation); they cannot appoint Safety Health Officer (SHO) to handle the site safety; have limited external resource; and also small grade contractors have financial constraints. Based on this review, it can be concluded that small grade contractors have more lacking in safety management and consequently, the rate of accidents still higher in the construction industry. However, safety management in small grade contractors can be improved with support by external resources such as researcher, large grade contractor, government, and pressure from authorities.
\end{abstract}

\section{Introduction}

The construction industry continues to play a big role in the development as many construction activities have been carried out to meet the highest demand of the expensive market. The construction industry is a complex practice by nature due to fragmented working processes, which involve many stakeholders [1]. The construction project was conducted by numbers of a player such as contractors, consultant, engineer, and client. The vast majority of a construction company are small grade contractors that rely on outsourcing personnel as required [2],[3]. Small grade contractors are constitutes over $99 \%$ of construction sectors in United Kingdom (UK); more than $99 \%$ in European Union (EU) and $97.3 \%$ in Malaysia [4],[5],[6],[7],[8], [9],[10],[11],[12],[13],[14]. Small grade contractors are vital to the construction industry operates in order to improve the overall performance of construction industries across the world [8].

The definition of small grade contractors varies from country to country. Small grade contractors are defined broadly as one with limited capital investment, who may need financial and managerial support to run their business [15] effectively. In this study, micro grade contractors (G1) and small grade contractors (G2-G4) was merge as small grade contractor's categories and have the same definition. For small grade contractors, creating an enabling environment includes removal of barriers to their entry into the market and to their growth and sustainability.

Small grade contractors can be a powerful mechanism of generating job opportunities, and they have been long believed to be important in supporting and contribute positively to the economics of the country [16] [17] [18]. In addition, small grade contractors also can perform small project at different and remote

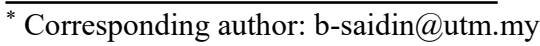


geographical locations that might be unattractive to large grade contractors, or it is too costly using the large grade contractors [18].

However, the project value for small grade contractors is limited based on grades. The previous study was summarizing that the value of the project for small grade contractors as represented in Table 1. Consequently, small grade contractors have limitation to take of the project and they only can conduct the project not exceeding RM3,000,000. The works categories in the construction industry are civil works, building works, mechanical and electrical works. Basically, small grade contractors will conduct the projects renovation, maintenance, and new building.

Table 1. Summary of project tender limitation.

\begin{tabular}{|c|c|l|}
\hline Company Size & Project value & \multicolumn{1}{|c|}{ Sources } \\
\hline \multirow{2}{*}{ Micro (G1) } & Not exceed RM300, 000 & {$[28]$} \\
\cline { 2 - 3 } & Not exceed RM200,000 & {$[2]$} \\
\hline \multirow{3}{*}{$\begin{array}{c}\text { Small } \\
(G 2-G 4)\end{array}$} & Not exceed 50,000,000 Bath & {$[16]$} \\
\cline { 2 - 3 } & Not exceed \$2,500,000 & {$[18]$} \\
\cline { 2 - 3 } & RM 300,000-RM 3,000,000 & {$[28]$} \\
\cline { 2 - 3 } & RM 200,000-RM 3,000, 000 & {$[2]$} \\
\hline \multirow{2}{*}{$\begin{array}{c}\text { Medium } \\
\text { (G5-G6) }\end{array}$} & Not exceed 200,000,000 Bath & {$[8]$} \\
\cline { 2 - 3 } & Not exceed RM 10,000,000 & {$[17]$} \\
\cline { 2 - 3 } & Not exceed RM 20,000,000 & {$[28]$} \\
\hline Large (G7) & Unlimited & {$[17],[28]$} \\
\hline
\end{tabular}

Unfortunately, the construction industry also exposed to highest risk and most hazardous industry due to fatality rate is five times more likely than the other industry [19],[20],[21]. According to previous research, the small grade contractors endure a greater burden of accidents in construction industry compare to large grade contractors [4],[22],[6],[10],[11],[7],[23],[24],[25],[26]. Referring to [27], the accident does not just happen, it may cause by unsafe acts, unsafe conditions or both. Additionally, the causes of the most accidents in the construction industry are also mainly attributable to management negligence or inadequate workers safety awareness [22].

To prevent accidents, one must know the causes of the accidents in the working environment such as inherently hazardous construction project, what is the safety practice that implements at the workplace, personal and project factors, and mechanisms or equipment that lead to accidents. Effective safety approaches may be taken to prevent and minimize reoccurrences in the future [1].

\section{Challenges faced by small grade contractors in safety practice}

Issues on safety are the major problem in the construction industry. The construction industry also has been identified as one of the most dangerous industry as stated in the Social Security Organization (SOCSO) [27], [29]. In fact, the safety part in construction work is entirely subjective, and such a complex phenomenon of study to implement due to the industrial safety has undergone significant changes over the past decade.

\subsection{High competition between small grade contractors}

The small grade contractors are dominant in the construction industry, but they are largely unregistered, operate in the informal sector of the economy and minimal formal business systems [3]. In Malaysia, the total of local contractors $(76,651)$ that were registered with CIDB from 2014 until 2016 as showed in Fig. 1. There was a sharp increase of $11.5 \%$ from $2014(67,833$ contractors) to 2016. Surprisingly, the G1 to G3 contractors show the highest registration in CIDB, which amount to $59,666(10.66 \%)$ contractors in 2016 [2].

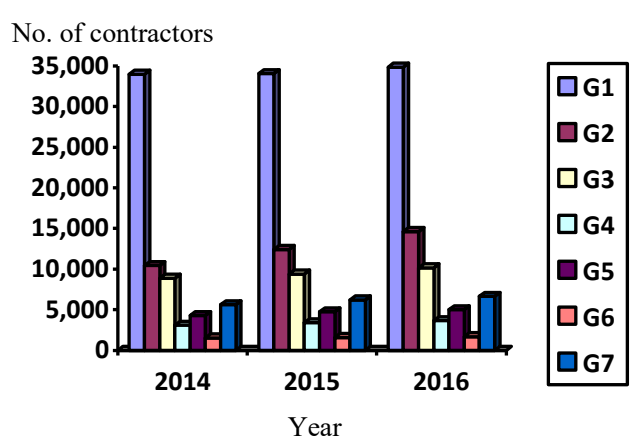

Fig. 1. Number of contractors registration with CIDB.

Based on this statistic, it can be concluded that the small grade contractors have the highest number of companies in this construction field rather than large grade contractors. Consequently, small grade contractor facing increased competition due to the real long-term decline in demand, and many contractors have responded by shedding labour [3]. Large grade contractors responded by moving into the international market, and they can choose who they want (small grade contractors) as the subcontractor. Because of that, small grade contractor try to tackle large grade contractor by putting the lowest price in their project tender and at the same time they try to maximize their profit. Usually, subcontractor will cut cost from the safety part in project tender in order to increase their profit. As known, the contractor (main or sub-contractor) must be provided with the Personal Protective Equipment (PPE) in good condition for every project. If the PPE is not in good condition such as not function as usual, the contractors should be replaced for the new equipment to avoid the accidents occur at the workplace. The PPE equipment must be checked before a project start to make sure that the equipment fully functional and workability. Unfortunately, most of the contractors in the construction industry did not practice and implement safety accordingly in the workplace. Because of that, the safety practice in small grade contractors is still lacking, and the accident cannot be reduced effectively.

\subsection{Highest accident}

The DOSH Ministry of Human Resources most recently recorded a worrying rise in accidents in the construction industry [30]. The number of fatal accidents occurred in 
Malaysia alone saw a highly dominated figure coming from the construction sectors as represented in Fig. 2 [12]. These reports on accidents merely only describe the cases of accidents, but did not mention the factors that lead to those accidents. According to [30], the common factors causing an increased risk of injury to workers are when they are involved to unsafe act during working; lack of safety management; OSH management problems; lack of awareness and law; unskilled workers and hazardous work environment.



Fig. 2. Statistic of a fatal accident by sector in the year 2017 [14].

Small grade contractors are compromised in the construction market and also have high accident rates $[4],[22],[10],[31],[7],[32],[25]$. According to [25] the ergonomic, physical and chemical work environment is also more hazardous in small grade contractors than the largest ones. The Fig. 3 shows the accidents statistic in construction industry according to the grade of contractors. Surprisingly, the statistic shows the small grade contractors experienced the highest accident in the construction industry since 2000-2007. Basically, small grade contractors mainly contribute to less adequate management skills, less ability to implement safety and health works, insufficient worker safety awareness, failure in labour safety laws and regulations compliance and inadequate safety protection measures and facilities [22]. According to [22], the causes of occupational accident for small grade contractors is because of a lack of working experience, temporary workers, the employer did not provide proper PPE, the PPE did not correctly use, the safeguards and hazard warning sign were ignored or not used in the working environment, falls and tumbles. In addition, the employers have poor health and safety managing skills and often neglect health and safety training in the workplace makes an even greater contribution to the persistently high rate for occupational accident occurrence. Referring to Arewa and Sorenson [4],[25] the quality of safety and health management system and workplace assessment in small grade contractors is highly remarkable compared to medium and large grade contractors.

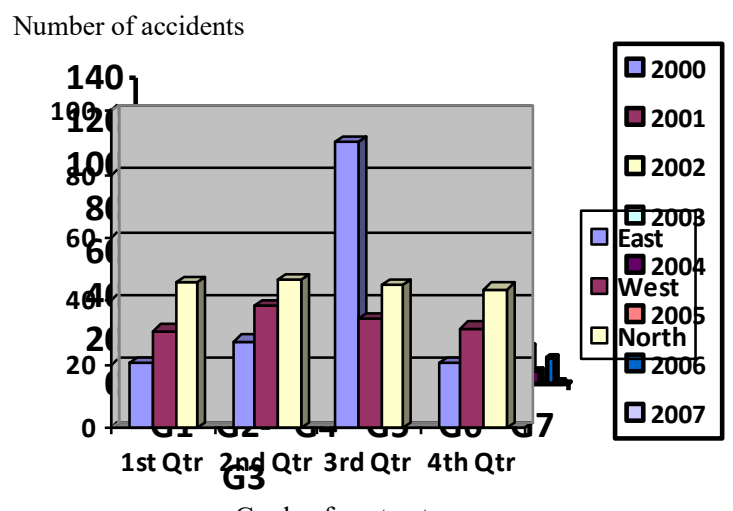

Fig. 3. Accident statistic by grade of contractor since 20002007.

\subsection{Lack of safety laws and regulations for small grade contractors}

In Malaysia, law and regulations in construction safety have been created and were established in 1967. The law and regulation of construction practiced at construction site are such as Factories and Machinery Act, Occupational Safety and Health Act, Guidelines on Occupational Safety and Health in Construction Industry, and Guidelines for Public Safety and Health [14]. [33], mentioned that a big gap between the statement in the policy and what actually happened in safety practice are widely stated in the policy but slightly implemented on site. The lack of enforcement from the authorities can cause the lack of safety implementation in construction site although Malaysia already has a good law and safety policies. This is because the supported, force and advice from the authorities is very important for small grade contractors in order to create the awareness and to improve the safety management in the workplace.

However, safety law and regulations are not enough if it stands alone without the assistance of another safety framework or safety system. Additionally, safety law and regulations in construction are too general, and it is not explicitly based on the grade of contractor such as small (G1-G4), medium (G5-6) and large (G7) contractor. Basically, contractor G5 to G7 are being implemented the existing construction safety law and regulations because the work environment, law and legislation on OHS have been mainly based on medium and large grade contractors and all requirements already fulfilled by them [34]. Every grade of contractors has their own characteristics which are the management of their company, speciality and the weaknesses. Consequently, based on the characteristic, not all of the contractors can implemented and follow the existing safety law and regulations in their company especially small grade contractors. 


\subsection{Safety personnel}

\subsubsection{Safety and health officer (SHO)}

According to [28], SHO will be appointed for the observation, opinion, advice their employer, and to handle the safety and health management on a construction site. The SHO has enough experience and excellent performance in construction safety with seen they have green book certificate proven by DOSH. Additionally, the SHO is directly workings under DOSH, and they always update on the issues and new regulation related to safety in a construction site.

Referring to DOSH requirement, the value of the project to appoint SHO should exceed RM20 Million. So, based on the requirement, large grade contractor (G7) can nominate SHO because the value of project for G7 is unlimited. Unfortunately, the small grade contractors cannot appoint $\mathrm{SHO}$ due to that requirement. The value of the project for small grade contractors is not exceeding RM3 Million. Financial insecure faced by small grade contractors is one of the barriers for them to appoint full-time safety personnel, and to arrange the formal safety management in their company [12]. Consequently, the small grade company implement the improper standard of safety management in construction site [33]. Small grade contractors have some problems with safety such as improper standard of safety law and regulations and lack of safety practice compared to medium and large grade contractors. It's supported by [35], whereby the large grade contractors with a high value of project show the good performance in safety management instead of small grade contractors.

\subsubsection{Site safety supervisor (SSS)}

The SSS is responsible for assisting the companies' manager in encouraging the safety and health of any person employed [2]. SSS can be appointed by small grade contractors as safety supervision for their company. The SSS can work around 15 hours per week or 3 hours per day as well as the job scope of SSS such as safety meeting, safety inspection on site and give toolbox meeting for their workers on site [2]. In addition, the limitation of employees in small grade contractor can cause the SSS to do the other works which are not related to safety matter. Consequently, SSS is not enough to handle the safety in construction due to time constraint and over workload.

The numbers of employees are not exceeding 30 people in most of the small grade contractor companies. [2]. Referring to DOSH [14], the employees in contractor companies should exceed 20 persons in order to engage one full-timer of SSS as to fulfil the DOSH requirement. Thus, only the small grade contractors with G4 can appoint one of SSS to handle everything on their site because the number of employees is exceeding 30 persons. However, contractors G1-G3 cannot appoint safety's personnel in charge (expert) because they were not fulfilling the requirement. The requirement is one of the factors that the small grade contractors lack in safety and cause the highest number of accident event that occurs in this industry.

\subsection{Employees in small grade contractors}

The accident rate in the construction industry was influenced by the small number of employees. The small grade contractors are the largest percentage of total contractors, although they had employed very few permanent staff, usually less than 10 employees [3]. According to [4],[22],[31],[34],[36],[17],[37], the employees less than 25 persons had very high accident rates occurred in most of the small grade contractors companies. Meaning, there will be more accident in the workplace would happen if there were a fewer number of employee in that company. As known as small grade contractors have fewer employees compared to large grade contractors. Table 2 shows the number of employees based on the contractor's grade.

Table 2. Number of employees in a construction company

\begin{tabular}{|c|c|l|}
\hline $\begin{array}{c}\text { Size of } \\
\text { company }\end{array}$ & \multicolumn{1}{|c|}{$\begin{array}{c}\text { Number of } \\
\text { employees }\end{array}$} & \multicolumn{1}{|c|}{ Sources } \\
\hline \multirow{4}{*}{ Micro (G1) } & $>10$ & {$[38,23,8]$} \\
\cline { 2 - 3 } & $1-9$ & {$[24]$} \\
\cline { 2 - 3 } & $>5$ & {$[28]$} \\
\hline \multirow{4}{*}{ Small (G2-G4) } & $>50$ & {$[16],[31],[7],[8]$} \\
\cline { 2 - 3 } & $10-29$ & {$[6]$} \\
\cline { 2 - 3 } & $>20$ & {$[6]$} \\
\cline { 2 - 3 } & $10-49$ & {$[24]$} \\
\cline { 2 - 3 } & $>10$ & {$[3]$} \\
\cline { 2 - 3 } & $11-50$ & {$[23]$} \\
\hline \multirow{4}{*}{ Medium (G5- } & $5-30$ & {$[28]$} \\
\cline { 2 - 3 } G6) & $30-199$ & {$[38]$} \\
\cline { 2 - 3 } & $>200$ & {$[8]$} \\
\cline { 2 - 3 } & $50-249$ & {$[24]$} \\
\cline { 2 - 3 } & $51-250$ & {$[23]$} \\
\hline Large (G7) & $30-75$ & {$[28]$} \\
\hline
\end{tabular}

The qualification of employees for small grade contractors usually is having low education, unskilled workers and they were also working as temporary workers. The owner or employer of small grade contractor also has little education. However, the construction industry has relied mainly on a core of highly skilled staff to supervise mostly unskilled workers. Unfortunately, the employers even were unacquainted and rarely bear with safety practice onsite. Because of that, the workers in small grade contractors work under unsafe condition due to the limitation of safety knowledge from employer and employees [39]. The safety knowledge is comparatively low compared to medium and large grade contractors [32]. Consequently, the employees should be responsible for their own selves if any accidents happen and/or risk. According to [1], every worker involved in a construction process must understand their rights and liabilities. The law facilitates the management of safety and health in a workplace. If an individual breaks the law, they will be the one 
personally liable for the consequences of their actions [1].

\subsection{Lack of resources}

The challenges faced by small grade contractor is lack of resources for training contractors, such as funds, poor construction procurement systems and lack of management capacity and resources to equip managers to operate their company effectively and efficiently [18],[3]. In addition, lack of effective management during early stages is a significant cause of company failure for small grade contractors. Poor safety record keeping is a cause for start-up safety practice in the company become failure [3].

Small grade contractors need external assistance such as large grade contractors, government, researcher and third parties in safety and health programming in order to get the advice and support for them [36]. Part of the enabling process may be to offer the small grade contractors support, which will facilities their access to the necessary resources to start and sustain their businesses. Governments have outsourced to the private sector some of the activities that were previously carried out in-house by government departments. Due to the absence of suitable small grade contractors in most countries, it has been found necessary to develop and empower small grade contractors to participate in contracting [15]. Unfortunately, they have limited access to external sources to support them in term of safety [34],[36]. Because of this problem, the workers in small grade contractors have been reported to accept and look at health risks as an individual responsibility due to informal social relations between employer and employees [31]. Thus, this makes it more difficult for small grade contractors to create and implement an excellent safe and healthy work environment in a construction site. Another challenge of construction safety faced by small grade contractors is the employer does not know how to manage the correct safety in the workplace, as well as the employees, are frequently exposed to hazardous situations and suffer more workrelated injuries and illnesses [34].

Therefore, small grade contractors withstand a greater burden of illnesses, fatalities and occupational injuries compared to large grade contractors [6]. The lacking of OHS management and safety outcomes in small grade contractors may be attributed to the characteristics of the company [34].

\subsection{Limited financial sources}

In terms of cost, small grade contractors operating faced financial pressure and limited financial sources due to short life-cycle [34]. It is because the time period for small grade contractors (especially G1-3) to complete the project will take about 2-4 weeks only. The delays with interim and final payments, as well as rigorous contract conditions faced by small grade contractors can also be enormous constraints on the industry. Many small grade contractors have suffered financial ruin and bankruptcy because of delays in payment, which are common with government contracts [3]. The owners or managers tend to manage their company themselves as a measure of reducing operational costs [3]. Small grade contractors need to spend more cost of remedy work such as fines, adverse safety and health incidents, rectification work, prosecutions and sentences. They also exposed to the higher risk and uncertainties of financial performance due to the highest cost of human capital and the destabilising effects of safety and health in construction site [4]. The financial constraint makes small grade contractors have trouble to apply and implement the safety management in the workplace due to the high cost. As known, the safety management and safety equipment in a construction site are quite expensive to implement and provided on site. The company need to spent more for SHO and SSS charge. This is one of the factors that the small grades contractors do not perform the good safety in the workplace compared to large grade contractors.

\section{Conclusions}

Based on this paper, it can be concluded that the small grade contractors are facing some issues related to safety practice in their company. This study found that the safety issues in small grade contractors such as the highest of competition to get the project, the barriers to appoint safety in charge, financial constraints, limitation of resources, and weaknesses of employees. The critical issues are the characteristic of small grade contractors have many flaws and they were also not fulfilled the safety government requirement. Consequently, the lacking of safety practice can increase the number of accident occurs in a construction site. Small grade contractors have many impediments in order to achieve the best safety implementation in their company, but the problems can be solved through to the critical research and support from the external sources like government, researcher and large grade contractors. Nonetheless, small grade contractors cannot improve the safety practice in their company without support from the external sources.

The authors would like to gratefully acknowledge that this paper as funded by a RADIS project grant, reference no. (PY/2017/01740).

\section{References}

1. H. Y. Chong, T. S. Low, accident in Malaysian construction industry: statistical data and court cases, 20, (2014)

2. CIDB, Construction industry development board executive director (2017)

3. W. D. Thawala, M. J. Phaladi, Small and medium size contractors in South Africa: 15 years of learning (2018) 
4. A. O. Arewa, P. Farrel, A review of compliance with health and safety regulations and economic performance in small and medium construction enterprise, ARCOM conference, in proceeding, p.p 423-432 (2012)

5. E. Cagno, G. J. L. Micheli, C. Jacinto, D. Masi, An interpretive model of occupational safety performance for small and medium sized enterprises, Int. J. Ind. Ergonomics, 1, 44 (2014)

6. T. R. Cunningham, R. Sinclair, Application of a model for delivering occupational safety and health to smaller business: Case study from the US, Safety Sc. 71, p.p 213-225 (2015)

7. N. A. Kheni, A. R. J. Dainty, A. G. F. Gibb, Health and safety management practices of small subcontractors, ARCOM conference, 1, p.p 7-9 (2005)

8. S. Lu, M. G. Sexton, C. Abbott, Key Characteristics of small construction firms: a UK perspective, 10 (2006)

9. A. Rostami, J. Sommerville, I. L. Wong, C. Lee, Risk management implementation in small and medium enterprises in the UK construction industry, 22, 1 (2015)

10. A. Dabrowski, An investigation and analysis of safety issues in Polish small construction plants, Int. J. Occ. Safety and Ergonomic, 4, 21 (2015)

11. B. M. Keller, T. R. Cunningham, Firefighters as distributors of workplace safety and health information to small businesses, p.p 87-91 (2016)

12. R. Y. Sunindijo, Improving safety among small organisations in the construction industry: key barriers and improvement strategies, 125 (2015)

13. S. Unnikrishnan, R. Iqbal, A. Singh, I. M. Nimkar, Safety management practices in small and medium enterprises in India, 1, 6 (2015

14. DOSH, Statistik kemalangan pekerjaan mengikut sector sehingga Julai 2017 (2017)

15. P. J. Kulameka, G. Kululanga, D. Morton, Critical factors inhibiting performance of small and medium scale contractors in Sub-Saharan region: A case study for Malawi, J. (2015)

16. C. Chittithaworn, A. Islam, T. Keawchana, D. H. M. Yusuf, Factors affecting business success of small and medium enterprises in Thailand, Asian Soc. Sc. 5, 7 (2011)

17. N. Yusof, M. S. Misnan, S. A. A. Hamid, Safety activities issues in small grade contractors, ISSN 1882-5796, p.p 276-281 (2018 a)

18. W. D. Thwala, M. Mvubu, Problem facing small and medium size contractors in Swaziland, J. 4, 2 (2009)

19. A. Bakri, R. M. Zin, M. S. Misnan, A. H. Mohamed, Occupational Safety Health Management System: Towards development of safety and health culture, ASPEC, in proceeding, 9, p.p 19-28 (2006)
20. Z. A. Zulkifli, Safety management ethics for construction industry (2012)

21. T. Aksorn, B. H.W. Hadikusumo, Critical success factors influencing safety program performance in Thai construction projects, 46 (2008) p.p 709-727

22. C. Cheng, S. Leu, C. Lin, C. Fan, Characteristic analysis of occupational accident at small construction enterprises, Safety Science, 6, 48 (2010)

23. V. Nyirenda, Y. Chinniah, B. Agard, identifying key factors for an occupational health and safety risk estimation tool in small and medium size enterprises, 3, 28 (2015)

24. M. S. Canamares, B. M. V. Escribano, M. N. G. Garcia, A. R. Barriuso, A. R. Saiz, Occupational risk-prevention diagnosis: A study of construction SMEs in Spain, 92 (2017)

25. O. H. Sorenson, P. Hasle, E. Bach, Working in small enterprises- is there a special risk? 10, 45 (2007)

26. M. N. Ozmec, I. L. Karlsen, P. Kines, L. P. S. Andersen, K. J. Nealsen, Negotiationg safety practice in small constructions companies $\mathbf{7 1}$ (2015)

27. A. R. A. Hamid, M. Z. A. Majid, B. Singh, Cause of accident at construction site, 202, 20 (2008)

28. DOSH, Strategic plan for occupational safety and health in small and medium industry sectors 20162020 (2016)

29. S. Unnikrishnan, R. Iqbal, A. Singh, I. M. Nimkar, Safety management practices in small and medium enterprises in India, 1, 6 (2015)

30. D. N. M. A. Abdullah, G. C. M. Wern, An analysis of accidents statistics in Malaysian construction sector, 3 (2011)

31. A. K. Holte, K. Kjestveit, H. J. Lipscomb, Company size and differences in injury prevalence among apprentices in building and construction in Norway, Safety Sc. J. p.p 205-212 (2015)

32. I. Mohammadfam, F. Ghasemi, O. Kalatpour, A. Moghimbeigi, Constructing a Bayesian network model for improving safety behaviour of employees at workplaces, 58 (2017)

33. S. Laryea, S. Mensah, Health and safety on construction site in Ghana (2010)

34. S. J. Legg, K. B. Olsen, I. S. Laird, P. Hasle, Managing safety in small and medium enterprises, 71 (2015)

35. C. R. C. Hassan, O. J. Basha', W. H. W. Lipscomb, Perceptions of building construction workers towards safety, health and environment, 3, 2 (2007)

36. R. C. Sinclair, T. R. Cunningham, Safety activities in small businesses. Safety Sc. J. 64, p.p 32-38 (2014)

37. M. Gunduz, H. Laitinen, A10- step safety management framework for construction SMEs, (2016) 
38. N. A. Kheni, Impact of health and safety management on safety performance of small and medium-sized construction businesses in Ghana (2008)

39. N. Yusof, M. S. Misnan, Restrictions to implement safety practice in small grade contractors $(2018 \mathrm{~b})$ 